\title{
Postcards from the Edge of SoTL: A View from Faculty Development
}

\begin{abstract}
As a past SoTL scholar turned faculty developer, I have come to realize that SoTL is a mindset: one of questioning old assumptions about what teaching entails and how our students learn, gathering and examining evidence of the effects of our approaches, and reflecting on and sharing insights gained. This perspective changed my own teaching. Now it informs each consultation I have with faculty, upending much of what faculty traditionally believe about teaching on intellectual, social, and personal levels. By adjusting the frame through which we view teaching, SoTL has revelatory power in catalyzing change. In this article, I discuss how key precepts of SoTL enhance the day-to-day work of faculty development. Specifically, through SoTL, faculty realize that course design is an intellectual endeavor, that students are complex individuals from whom they can learn, and that teaching is an ongoing transformational journey to be shared.
\end{abstract}

\section{KEYWORDS}

faculty development; educational development; faculty beliefs; pedagogical change.

A number of years ago I had the good fortune of being selected as a Scholar by the Carnegie Academy for the Scholarship of Teaching and Learning (CASTL), an initiative of the Carnegie Foundation for the Advancement of Teaching in the United States. That program selected faculty in specific disciplinary cohorts to develop projects on the Scholarship of Teaching and Learning (SoTL) in a collaborative, "think tank" experience. As a faculty member from a small liberal arts college, I was specifically interested in how certain pedagogical approaches, such as problem-based learning, might help promote students' deep learning.

In retrospect, my project was rather naïve, at least in the sense of my being able to gather definitive data to show discernible differences in student learning in a class of 24 students in a single semester. But the experience of thinking about my teaching as scholarship, sharing and critiquing ideas with my peers, was life-changing. At the end of my two-year CASTL Scholar experience, I left the professoriate and transitioned into faculty development with the view of continuing this collaborative, scholarly examination of student learning with a larger group of faculty.

There, too, I discovered a distinct difference between my vision of faculty develop- 
ment work and the reality. Ostensibly, in transitioning from faculty to faculty developer I moved from being a SoTL practitioner to a SoTL promoter. In reality, however, my first position in faculty development was in a center for teaching and learning at an elite research university. That institution had many fine, dedicated teacher-scholars, but SoTL was not something that was viable for the vast majority of tenure-stream faculty there. My role was to support their day-to-day instructional work, helping them deal in a time-efficient manner with what they perceived as problems in their teaching or their students' learning.

So in many ways I stepped back from SoTL work. But I realized that the CASTL immersion into SoTL had catalyzed a transformation in the way I viewed teaching and learning that transcended any individual project or the overall practice. I realized that SoTL is a mindset: one of questioning old assumptions about what teaching entails and how our students learn, gathering and examining evidence of the effects of our approaches, and reflecting on and sharing insights gained. This perspective changed my own teaching. Now it informs each consultation I have with faculty, upending much of what faculty traditionally believe about teaching on intellectual, social, and personal levels. By adjusting the frame through which we view teaching, SoTL has revelatory power in catalyzing change. Issues in teaching become about addressing challenges in human cognition, in developing disciplinary expertise, and in overcoming epistemological conflicts. Through SoTL, the language of teaching now echoes the language of disciplinary work (Hutchings, Huber, \& Ciccone, 2011) and engages the scholar's mind.

Many other fine scholars have chronicled what SoTL is and is not, what they have uncovered about student learning through the process of SoTL, what they have learned about promoting SoTL in their institutions, and where SoTL is in its history, current status and future needs. In this article, I discuss how key precepts of SoTL enhance the dayto-day work of faculty development. Through the SoTL perspective, faculty realize that course design is an intellectual endeavor, that students are complex individuals from whom they can learn, and that teaching is an ongoing transformational journey to be shared.

\section{CATALYZING CHANGE IN FACULTY APPROACHES TO COURSES}

Faculty as scholars all begin with a goal, a thesis or a hypothesis, when approaching their disciplinary research. Interestingly, this approach is not the traditional method used when designing courses. The principles of backward course design (Wiggins \& McTighe, 1998), that is, starting with goals and aligning assessments and assignments to serve those goals, is still novel for many faculty. Faculty may be familiar with the need for course learning goals because of institutional assessment requirements. Some faculty, however, resist articulating course goals even for that purpose. They may feel that many of their goals for student learning transcend content or skills and are immeasurable by conventional means. Faculty in general may consider the need for assessment of learning goals as an undue burden or a suspicious bureaucratic exercise. They often do not internalize the concept of beginning with the end in mind as a vision to direct ongoing course and curriculum development and revision.

As I work with faculty in thinking through course issues or designing courses, my query of "What do you want students to come away with after the course?" or "What do you want to accomplish in this course?" often evokes a thoughtful silence. This interval is usually followed by passionate responses chronicling their highest-order ambitions for their students. These aspirations have power to motivate faculty as well as students, providing 
direction and clarity for everything from class format to assessments and assignments. These goals may not always be readily measureable. What is most important, however, is that the goals can be clearly communicated to students and that students have some reasonable chance at achieving them within the time allotted to the courses. In disciplinary work, faculty may strive to prove theses and hypotheses that are not easily substantiated. The loftier the goal, the more intentionally they must refine their questions and design methods and data collection to achieve those aims. So it is with course goals and design.

Once faculty articulate their goals, whether lofty or pragmatic, we work together to imagine what it would look like if students achieved them. What kind of disciplinary work would allow students to demonstrate that they have achieved these understandings, these mindsets, that faculty wish for them? In a sense, what will this evidence look like? Finally, we focus on challenges that novices face in learning how to do work in our fields, and we think about the kinds of course activities and assignments that help students build the framework of skills or habits of mind or attitudes necessary to meet these challenges. This conversation often reveals a faculty member's prior experience with assignments that were not as successful as they hoped in developing students' abilities. At that point, we brainstorm new ways to lead students into our disciplinary work. This process makes explicit that each course is a continual work in progress and helps faculty understand the logic in closing the loop-why tracking whether their goals have been achieved, either short-term or long-term, makes sense.

In Randy Bass' eloquent narrative about his pathway into SoTL (1999), he described how he transitioned from trying to "fix" a teaching issue to recognizing the ongoing intellectual "problem" of teaching:

My journey that had begun with a crisis had progressed to a problem, in fact a set of problems. The ending had become a new beginning where the broad set of questions that had been raised in the process of rethinking my courses were now coming into focus as clear lines of inquiry that I wanted to investigate over the next several years, in the context of my teaching. (para. 12)

In essence, as a faculty developer, I guide faculty into thinking of their courses as intellectual "projects," whether they actively engage in SoTL or not. This view not only helps faculty make sense of institutional assessment requirements, but also, more importantly, it validates the complexity of their work as teachers and reveals the impact that their teaching has on student learning. As faculty workloads increase and personal rewards dwindle, the generative power of completing a well-designed course with demonstrated results and new areas of inquiry can provide purpose and meaning at the end of the day.

\section{CATALYZING CHANGE IN FACULTY UNDERSTANDING OF STUDENT BEHAVIOR}

The complicating element in course design is, of course, the student. Teaching is not only an intellectual activity; it is also a social one. Faculty often begin a consultation with me with a litany of complaints about students, even if they like students and enjoy teaching. Or they may be puzzled by the changing student population, not sure why a teaching approach that worked for them in the past no longer results in good teaching evaluations. They describe students as less prepared for college work, less willing to prepare for courses, 
and less able to study effectively than prior groups of students or as the faculty member was as a student. Certainly, the student demographic in higher education is changing, and faculty observations of changing student characteristics are often real. The Millennial Learners in particular (students born between 1982 and 2001 or so) have a different view of authority in the classroom and the professor's role (Price, 2009). But many challenges faculty face with students are not new with the Millennial Generation. And in addition, there are simply more students and a greater variety of students than in the past.

As faculty, we often tend to take student behavior personally. We may be offended or frustrated by behaviors in students that seem rude, that show an apparent lack of interest or respect. Parker Palmer, in his moving and insightful work, The Courage to Teach (1998), tells the story of encountering the "universal archetype" of the "Student from Hell" (p. 43). While delivering a guest lecture at another university, Palmer's attention was captured by a student in the classroom's back row. He was slouching, almost horizontal to the floor, apparently exhibiting an arrogant lack of interest in Palmer's talk. Palmer found himself directing all his attention at that student, trying to engage him, expending energy to convert that student to his side. At the end, Palmer left feeling "self-pity, fraudulence, and rage" (p. 43). Imagine his dismay then when he found that this student was driving him back to the airport. He recounts:

I will always remember the conversation that followed. The student's father was an unemployed laborer and an alcoholic who thought that his son's desire to finish college and become some kind of professional was utter nonsense.

The young man lived with his father, who berated him daily for his foolishness...

Daily this young man felt his motivation for college fading away. "Have you ever been in a situation like this?" he asked. "What do you think I should do about it?"

We talked until it was time for my plane to take off, and for a while afterward we corresponded. I do not know whether I helped him-but I know that he helped me. He helped me to understand that the silent and seemingly sullen students in our classroom are not brain-dead: they are full offear.

... [T] his student-whose plight is like many others-forced me into a deeper understanding of the student condition, one that is slowly transforming the way I teach. (p. 45)

The only way we know what motivates students, what they think or feel, is to talk with them. Traditionally, the social, relational nature of the classroom is often covert until faculty see their end-of-term student evaluations. At that point, the illusions that faculty have about the meaning and impact of their teaching may be shattered by the "judgment of the young" (Palmer, 1998, p. 48). The SoTL mindset recognizes the classroom as an overt social arena populated by real people with varying expectations, talents, and interests. Specifically, the SoTL emphasis on evidence has always included not only objective data on student learning, but also the witness of student voices. SoTL practitioners gather insights on student learning by surveying them on facets such as their motivation, 
approaches to study, and attitudes toward learning, for example. Faculty collect glimpses into the way students think through active listening exercises such as think-alouds.

In addition, the SoTL mindset includes students not only or primarily as objects of study, but also as collaborators. Former students, outside the class being studied, may act as colleagues, providing insights into the student view, helping with both the design of projects and the interpretation of results. The fact that SoTL often involves faculty studying their own practice, a distinction that separates SoTL from most classic education research, is one testimony to this collaborative view. We learn from and with our own students.

The SoTL perspective also guides faculty in re-examining the teacher-learner dynamic through its emphasis on learning from the work of others. As faculty, we often have no perspective on student learning other than our own personal experience as students. Even that limited view has been distorted by lapses in memory and the revisionist impact of all that came after. The literature, however, abounds with insights on how novice students learn compared to experts, their beliefs about how learning works and the role of the teacher, and how they are motivated or not by various circumstances in their life and coursework. The SoTL perspective moves us to rethink our view that student behavior is somehow a personal affront aimed at the teacher. Instead we recognize that students are acting from where they are, from their combined experiences and lack thereof, and their states of cognitive, social, and epistemological development.

\section{CATALYZING CHANGE IN HOW FACULTY UNDERSTAND THEMSELVES AS TEACHERS}

Teaching is an intensely personal endeavor. Although the SoTL perspective may help us as faculty re-envision our courses and our relationship with our students, it may or may not in itself trigger an overall shift in how we view our role as teachers. That transformation may require a crisis moment, a moment when we confront the realization that our teaching no longer serves the role or purpose that we had imagined in our work. Sometimes this re-examination may be catalyzed by the stress associated with low student evaluations or the daily wear and tear of teaching. When that moment comes, SoTL can provide a scaffold for re-inventing ourselves.

Numerous studies and models exist on the complex construct of faculty beliefs and how they develop (or not) over time. For example, faculty may see themselves as providing opportunities for learning, as facilitating learning, or as effecting learning (Arreola, 2007). Pratt characterized five perspectives of faculty on teaching: transmission, apprenticeship, developmental, nurturing, and social reform (1998). Yet another group of studies on faculty conceptions of teaching categorized faculty as having a teacher or content focus, with an emphasis on transmission of content, or a student focus with an emphasis on developing or changing conceptions (Trigwell, Prosser, \& Taylor, 1994). All of these models define some responsibilities of teachers for their students, and in one way or the other, all of these models place an expectation on faculty for performance. Performance in this case may mean giving lectures, answering student questions, grading student work, facilitating discussion, or guiding group work. And performance can be a source of anxiety.

Studies have shown that faculty report the act of teaching as producing anxiety (Ameen, Guffey, \& Jackson, 2002; Fraser, Houlihan, Fenwick, Fish, \& Möller, 2007; Gardner \& Leak, 1994). Anxiety may arise from the fear of public speaking, but dealing with stu- 
dent questions, behavior, and evaluation also contributes (Fraser, et al., 2007; Gardner \& Leak, 1994). The anxiety associated with the act of teaching does lessen as faculty get more experience, but the anxiety associated with dealing with students does not. The more anxious faculty report feeling, the more likely they are to minimize interactions with students (Fraser, et al., 2007). As faculty, the reason for our anxiety is complex, but one aspect certainly is the fear of failure and embarrassment. We may worry about not knowing the answer to student questions, forgetting or neglecting important ideas, or looking foolish in the process of teaching.

Fear is only one of the negative emotions that are frequently associated with teaching; another is frustration. As faculty we spend hours on teaching-preparing, grading, and advising students. We are passionate about our disciplines and want to transmit our love of the field to our students. Often we gain a great sense of worth through our teaching: we hope to effect change and make an impact on the next generation. But as I discussed above, today's students may not share our interest or understand our motivation. If we project our own values and goals onto students without understanding both the different stance that students take on courses and the different needs of the novice learner, the result can be devastating to our morale. This fear or frustration can immobilize us or it can act as a stimulus to change. Douglas Robertson proposed a faculty development model that includes three phases in how faculty perceive their teaching, each phase including and extending the views of the previous (1999). In his model, faculty move from a teachercentered view, to a learner-centered view, and finally to a perspective that views teacher and learner as interconnected in the dynamic of learning. When faculty face a challenge in their current view of teaching, they either transition back to the familiar or move forward to the next stage in their development. The direction they choose depends on how well they can deal with the discomfort and feelings of loss associated with the change.

SoTL provides a framework to support these transitions (Hodges, 2004). First and foremost, a hallmark of SoTL is its emphasis on teaching as community property, a move away from the common situation of pedagogical isolation that Lee Shulman, the past president of the Carnegie Foundation for the Advancement of Teaching, so eloquently described (1993). As a faculty developer, I can route faculty who face disorienting and discomfiting situations in their teaching to a wealth of resources through the teaching commons (Huber \& Hutchings, 2005) - research literature, faculty development consultations, and faculty peers in workshops. Faculty realize that they are not alone and that they have viable choices.

Second, as a consultant I can help faculty reframe this challenge using a question Shulman often posed when speaking about SoTL_- "What is this a case of?" Instead of starting from the viewpoint that the faculty member's teaching is faulty, together we examine aspects of student learning and intellectual development that may be contributing to the situation. The SoTL perspective becomes a "back door" into discussions of teaching effectiveness (McCrickerd, 2012, p. 62). The extensive research on novice versus expert learners in various fields provides insights about student cognitive development that can inform faculty on differences in the way that students both perceive and process new knowledge. The work on Decoding the Disciplines (Middendorf \& Pace, 2008) provides a source of rich conversation about specific disciplinary roadblocks to student learning. Drawing from such pertinent literature, as a consultant I propose ways that might more 
successfully address the teaching issues that faculty face. The view of the faculty member's responsibility shifts from performance to process.

Finally, for some faculty, turning their teaching "problem" into an intellectual problem (Bass, 1999), one that they can systematically investigate, re-invigorates their teaching and gives new meaning to their work. For them as for me, the SoTL perspective brings wholeness to our work as teacher-scholar, closing the perceived divide between research and teaching. The SoTL community provides a fellowship of like-minded thinkers that relieve the feelings of loneliness and anxiety that we can otherwise experience in our teaching. And the SoTL movement reaffirms the status of teaching through its emphasis on the complexities of student learning, the gathering of evidence to inform practice, and the imperative to publicize our results to further the profession.

Dean McManus chronicled such a journey of discovery about his teaching in his memoir, Leaving the Lectern (2005). He detailed the various crises in his teaching, his fears, his learning from his students and from the teaching commons, and the shift in his understanding of who he was as a teacher. He summed up his story by encouraging others to "welcome the joy":

Our research in our discipline is exciting and fulfilling. And, yes, it is hard work. But we forget the difficulties when we thrill to finally stating the problem in such a way that it can be solved, when we reason the solution, when the analysis works, and when the synthesis holds firm. What a joyous feeling!...The change in your teaching will enable you to transfer that joy of accomplishment to your classroom, for there will be external validation of your accomplishment.

... [W] hen your desired accomplishment is to enable students to learn what you want them to learn and to use that learning, your accomplishment is judged not by you alone, but by feedback between you and your students and your reflection and adaptation in response... When the voice of the teacher within tells you that what you are doing is right for you -and for your students - your joy, enthusiasm, and excitement will be infectious. (p. 173)

\section{CONCLUSION}

In summary, SoTL provides faculty developers with a philosophy, a perspective, and a practice to offer faculty in their work as teachers. The SoTL philosophy allows developers to reframe faculty teaching issues. Consultants can help faculty move from thinking of teaching as performance to viewing their teaching as an intellectual process of course design and exploration of student learning. The SoTL perspective allows developers to redirect faculty frustration with student behavior. Through sharing the research literature and by encouraging faculty to open channels of communication with students, developers can help faculty members become more aware of, and responsive to, the different experiences, motivations, and understandings that today's novice students bring to the social community known as the classroom. Finally, the practice of SoTL allows developers to re-invigorate faculty who have reached a crisis in their personal understanding of themselves as teachers. They can offer faculty a new vision of purpose: teaching as scholarship. 
Consultants can help faculty explore intriguing questions about student learning, design and collect evidence to answer those questions, and share results with the broader community of scholars.

From my view as a faculty developer working on the edges of SoTL, I see the power of SoTL to effect change in higher education broadly and in distinct institutions. But perhaps most satisfying to me, I see the power of SoTL to effect change in individual faculty, making their lives richer and more rewarding.

Linda Hodges is Associate Vice Provost for Faculty Affairs and Director of the Faculty Development Center at the University of Maryland, Baltimore County.

\section{REFERENCES}

Ameen, E. C., Guffey, D. M., \& Jackson, C. (2002). Evidence of teaching anxiety among accounting educators. Journal of Education for Business, 78(1), 16-22.

Arreola, R. A. (2007). Developing a comprehensive faculty evaluation system ( ${ }^{\text {rd }}$ ed.). Bolton, MA: Anker.

Bass, R. (1999). The scholarship of teaching: What's the problem? Inventio: Creative Thinking about Learning and Teaching, 1(1).

Fraser, I., Houlihan, M., Fenwick, K., Fish, T., \& Möller, C. (2007). Teaching anxiety and teaching methods of university professors: A correlational analysis. AABSS Journal, 78-90.

Gardner, L. E., \& Leak, G. K. (1994). Characteristics and correlates of teaching anxiety among college psychology teachers. Teaching of Psychology, 21, 28-32.

Hodges, L. C. (2004). The "problem" as metaphor in teaching. Thought and Action, 20, 39-48.

Huber, M. T., \& Hutchings, P. (2005). The advancement of learning: Building the teaching commons. San Francisco, CA: Jossey-Bass.

Hutchings, P., Huber, M. T., \& Ciccone, A. (2011). Scholarship of teaching and learning reconsidered: Institutional integration and impact. San Francisco, CA: Jossey-Bass.

McCrickerd, J. (2012). Understanding and reducing faculty reluctance to improve teaching. College Teaching, 60, 56-64.

McManus, D. (2005). Leaving the lectern: Cooperative learning and the critical first days of students working in groups. Bolton, MA: Anker.

Middendorf, J., \& Pace, D. (2008). Easing entry into the scholarship of teaching and learning through focused assessments: The "Decoding the Disciplines" Approach. To Improve the Academy, 26, 53-67.

Palmer, P. J. (1998). The courage to teach: Exploring the inner landscape of a teacher's life. San Francisco, CA: Jossey-Bass.

Pratt, D. (1998). Five perspectives of teaching in adult and higher education. Malabar, FL: Krieger.

Price, C. (2009). Why don't my students think I'm groovy?: The new "R's" for engaging Millennial learners In S. A. Meyers \& J. R. Stowell (Eds.), Essays from e-xcellence in teaching (Vol. 9, pp. 29-34). Retrieved from the Society for the Teaching of Psychology Web site: http://teachpsych.org/ebooks/eit2009/index.php

Robertson, D. (1999). Professors' perspectives on their teaching: A new construct and developmental model. Innovative Higher Education, 23(4), 271-294. 
Shulman, L. (1993). Teaching as community property. Change, 25(6), 6-7.

Trigwell, K., Prosser, M., \& Taylor, P. (1994). Qualitative differences in approaches to teaching first year university science. Higher Education, 27, 75-84.

Wiggins, G., \& McTighe, J. (1998). Understanding by design. Alexandria, VA: Association for Supervision and Curriculum Development. 